\title{
Local Partners' Perspectives on Health Student Service-Learning Placements in Low- and Middle- Income Countries: A Pilot Qualitative Study with Partners from Vietnam and Timor-Leste
}

\author{
Emma Crawford ${ }^{a}$, *Anne E. Hill ${ }^{a}$, Anne-Maree Caine ${ }^{a b}$, Lucy Hunter $^{a}$, Allison \\ Mandrusiak $^{a}$ Ruth Dunwoodie ${ }^{a}$, Amy Fagan ${ }^{a}$, Teresa Quinlan ${ }^{a}$, Nataya Branjerdporn ${ }^{a}$, \\ Lisa Anemaat ${ }^{a}$ \\ a: The University of Queensland, Australia; b: Griffith University, Australia;
}

\begin{abstract}
Service-learning programs can provide clinical assistance in low-resourced settings while providing students with intercultural learning opportunities in diverse health contexts; local partners' perspectives on international service-learning (ISL) programs are integral to ethical, effective and sustainable university-community partnerships; yet the perspectives of local partners remain under-represented in research. Interpretive description methods guided data collection and thematic analysis of qualitative responses from written questionnaires. Four local partners from Vietnam and Timor-Leste responded to questionnaires in this pilot project. Three themes were identified regarding benefits, underpinning factors for program effectiveness, and a further three themes related to desired improvements. According to local partners, benefits of ISL include skill and knowledge exchange, enhanced assessment and intervention strategies, and increased service quality. Communication and relationships were seen as underpinning factors of effective partnerships. Areas for further improvement included drawing more strongly on local partner strengths and perspectives, further collaborative preparation for the placements, and more regular communication. These preliminary findings align with existing research regarding benefits to local partners. Modelling effective practices, formal training and meetings, and ongoing case discussions may be some useful methods for achieving knowledge and skill exchange in ISL
\end{abstract}

Keywords: global health; international service learning; professional education; therapy

*Corresponding Author: Dr Anne E. Hill PhD, School of Health and Rehabilitation Sciences, Discipline of Speech Pathology, St Lucia QLD 4072, The University of Queensland, AustraliaＥmail: ae.hill@uq.edu.au

Journal URL: https://publications.coventry.ac.uk/index.php/pblh

Crawford, E., Hill, A. E., Caine, A.-M., Hunter, L., Mandrusiak, A., Dunwoodie, R., Fagan, A., Quinlan, T., Branjerdporn, N., Anemaat, L. (2020). Local partners' perspectives on health student service-learning placements in low- and middle-income countries: A pilot qualitative study with partners from Vietnam and Timor-Leste. International Journal of Practice-based Learning in Health and Social Care, 8(2), 29-40. DOI 10.18552/ijpblhsc.v8i2.584

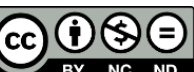

(C) 2020 Emma Crawford, Anne E. Hill, Anne-Maree Caine, Lucy Hunter, Allison Mandrusiak, Ruth Dunwoodie, Amy Fagan, Teresa Quinlan, Nataya Branjerdporn, \& Lisa Anemaat. This Open Access article is distributed under the terms of the Creative Commons Attribution Attribution-Non-Commercial No Derivatives 4.0 International License (https://creativecommons.org/licenses/by-nc-nd/4.0/ ), which permits unrestricted noncommercial use, distribution, and reproduction in any medium, provided the original work is properly cited and is unaltered. 


\section{Introduction}

The perspectives of local partners in international service learning (ISL) in low- and middle-income countries are integral to ethical, effective and sustainable university-community partnerships that allow for positive student outcomes and benefits to low-resourced settings (Chapman, 2018; Crump et al., 2010; Hayward \& Li, 2017; Rinaldo et al., 2015). Service learning is a structured learning experience that benefits the community as well as contributing to academic requirements for qualification. It combines active community engagement, explicit learning objectives, preparation, and reflection (Cipriani, 2017; Johnson \& Howell, 2017). At the time of writing, the World Bank defines low- and middle-income countries as having a Gross National Income per capita of less than \$3,895 (World Bank, 2019). In what follows, ISL partnerships between universities and local community partners will be considered in light of the benefits and challenges, the perspectives of students and faculty members, and the need for involving perspectives of international partners in understanding and evaluating ISL programs.

ISL is the implementation of service learning within a community outside of the country where the academic program is located. ISL often involves academic programs sending students from wealthier settings to less wealthy, low- and middle-income contexts (Crump et al., 2010; Lattanzi \& Pechak, 2011). Within allied health programs, ISL has been characterised by short-term (generally two to four weeks) experiences in underserved developing countries (Hayward \& Li, 2017; Lattanzi \& Pechak, 2011; Memmott et al., 2010). ISL as a way of offering student placement experiences has increased in response to the process of global interconnectedness, ease of access to means of travel, and recognition of the need for a culturally competent workforce (Beaman et al., 2018; Hayward \& Li, 2017; Pechak \& Thompson, 2009).

ISL involves a number of stakeholders including the academic institution, participating students, faculty members, individual recipients of services, the host community, and local partner organisations and their staff (Crump et al., 2010; Reisch, 2011). As a rich source of expertise in teaching and research in all sectors, universities are well placed to foster partnerships with communities (El-Jardali et al., 2018). A prominent form of university-community partnership is service learning (Atuyambe et al., 2016). The development and maintenance of a successful ISL program requires reciprocal university-community partnerships with clear long-term mutual benefits to all parties (Beran et al., 2016; Bowen \& Martens, 2006; Crump et al., 2010; Plumb et al., 2013).

The benefits and challenges of ISL for students, faculty members and academic programs have been well documented. A summary of student outcomes of ISL (Crawford et al., 2017) lists development of teamwork and collaborative practice, civic responsibility and ethical practice, interprofessional knowledge and skills, professional clinical skills, communication skills, self-confidence, self-awareness, and leadership skills as benefits to students participating in ISL. In addition, the immersion in diverse cultures has been found to result in increased cultural sensitivity and responsiveness, increased selfawareness around personal and cultural values, and magnified global perspectives throughout academic programs (Curtin et al., 2015; Pechak \& Black, 2013; Sabo et al., 2015). Service learning has also led to students developing increased understandings of other health care systems (Beaman et al., 2018) and differing views of disability and independence (Cipriani, 2017). Students engaging in ISL programs have been exposed to social determinants contributing to global health, including resource-limited environments as well as contexts of political complexities, violence, oppressive social structures, and poverty (Hayward \& Li, 2017). ISL experiences have also been found to be valuable in strengthening interprofessional practice and developing skills required for graduating health professionals, personal development, developing more mature world-views, and achievement of requirements for graduating health professionals in accredited occupational therapy, physiotherapy, speech pathology, and audiology programs (Crawford et al., 2017).

Challenges of ISL from the perspectives of students and faculty have included funding as a limiting factor for frequent visits to the host community, and student participation (Jesus, 2010; Pechak \& Black, 2013). Language and communication barriers due to students not speaking the local language have also been reported as challenges for students, faculty staff and international partners (Jesus, 2010; Pechak \& Black, 2013). 
To facilitate strong and ethical partnerships, sustained communication, well-structured programs, and the involvement of all stakeholders in the evaluation of ISL programs have been identified as integral (Crump et al., 2010; Lattanzi \& Pechak, 2011; Reisch, 2011). All parties have an obligation to strive to practise beneficence (to consciously encourage good outcomes) and non-maleficence (to consciously limit harmful outcomes); however, a number of ethical challenges are present in ISL (Lattanzi \& Pechak, 2011).

The ethical challenges of sustainability of services after students have departed, unbalanced relationships between university and community host stakeholders, and the burden placed on the host stakeholders in resource-constrained settings are widely documented (Crump et al., 2010; Lattanzi \& Pechak, 2011). While these challenges have been acknowledged in the literature, most research focuses on the perspectives of the academic institution, participating students, and faculty members (Hayward \& Li, 2017). Little is known about the perspectives of the local partners regarding ISL (Crump et al., 2010).

Principles and guidelines to support mutually beneficial partnerships for ISL in low- and middle-income countries have been espoused. For example, the seven Cs of ethically sound service-learning program development have been proposed as: compassion, curiosity, courage, collaboration, creativity, capacity building, and competence (McKinnon \& Fealy, 2011). Crump et al. (2010) have developed guidelines that prompt all stakeholders involved in service learning to actively take responsibility for: program structure; program goals; selection of students; training of students; communication; appropriateness of students' activities; safety; costs; supervision for students; feedback mechanisms; language skills; respect for divergent approaches to health; cultural sensitivity; licencing and legal aspects; donations; ethical research; sharing of information; and reciprocity. However, these guidelines are not founded on research that is reflective of local partners' perspectives.

An understanding of local partners' perspectives on ISL programs is critical, especially in low- and middle-income countries (Cipriani, 2017) which are low-resourced and where power imbalances between local partners and well-resourced academic institutions exist. It has been suggested that a lack of consideration of local partner perspectives results in a risk that participating faculty and students may cause harm, damage relationships with community partners, and place considerable burden on the host community (Lattanzi \& Pechak, 2011).

The core principles of ISL partnership are dependent on trust through interpersonal relationships and balance of power (Hayward \& Li, 2017). Communication with the host community, prior to and following the experiences, can avoid academic programs being seen as benevolent experts and can enable mutual understanding of the roles and skills of the students and international partners (Cipriani, 2017). To support the conduct of impactful and locally driven short-term ISL experiences, a number of frameworks have been developed (Hayward \& Li, 2017; Landry et al., 2012; Loh et al., 2015; Pechak \& Thompson, 2009). Despite these frameworks advocating local engagement, some did not involve international partner perspectives in their formation and development (Loh et al., 2015; Pechak \& Thompson, 2009). This points to the need for a collaborative approach to developing and evaluating ISL experiences.

Evaluation in university-community partnerships should place greater emphasis on iterative and frequent input from international partners alongside student and university faculty perspectives. The input from all stakeholders can strengthen evaluation design and improve the success and sustainability of partnerships (Bowen \& Martens, 2006). The inclusion of local host partner perspectives in evaluation of ISL learning experiences can also promote authentic and reciprocal dialogue, leading to continued relationships between university and local partner organisation (Hayward \& Li, 2017; Pechak \& Thompson, 2009). Despite the importance of including international partner perspectives in evaluating ISL partnerships, there is limited research available (Hayward et al., 2015).

Two studies have been conducted to evaluate an ISL partnership between a United States-based physiotherapy program and two host sites in Ecuador (Hayward \& Li, 2017; Hayward et al., 2015). Both studies analysed semi-structured interviews and quantitative surveys to gather the perspectives of student alumni and local partner organisation staff. Thematic analysis and descriptive statistics were used to describe the elements involved in beneficial partnerships and the associated challenges. Beneficial partnership elements included knowledge and skill development by local partners, meeting the needs of 
the partner, continuity of university-local partner relationships, and the donation of rehabilitation supplies (Hayward \& Li, 2017). Challenges in ISL partnerships included cultural barriers, lack of local language fluency, and concerns over the sustainability of newly acquired skills (Hayward \& Li, 2017; Hayward et al., 2015). While these studies consider the perspectives of international host partners, the findings are limited by geographical specificity to Ecuador. As this ISL experiences only involved students from a US-based physiotherapy program, the findings may not be relevant to interprofessional ISL involving students from countries outside the US.

Benefits to the international partners, as identified by faculty staff, have included education and faculty collaborations, particularly regarding evidence-based practice and opportunities to learn about other health care systems (Pechak \& Black, 2013). The qualitative study by Pechak \& Black (2013) evaluated the benefits and challenges of an ISL experience from the perspective of physiotherapy faculty members based in the US. While this study considers the challenges and benefits to the international partner, only US-based faculty members contributed their perspectives and they do not include the perspectives of students or international partners. Little research explores the benefits and challenges of ISL from the perspectives of the international host community (Crawford et al., 2017; Pechak \& Black, 2013).

There is also some research exploring community partner perspectives in the context of domestic servicelearning experiences (Atuyambe et al., 2016; Musolino \& Feehan, 2004). Atuyambe et al. (2016) explored both community partner staff and service user perspectives on Ugandan student service learning in Uganda, which gave deeper insight into challenges of service learning perceived by these stakeholders. These included students being perceived as an extra workload, some users not appreciating students' service, and some staff perceiving student presence as an opportunity to take leave. The challenges faced by partner organisations in service-learning programs indicate that their perspectives are integral to achieving successful outcomes for both universities and their partners. If workloads are too high or if student work is not perceived as useful, then the sustainability of these partnerships may be in jeopardy. While Atuyambe et al. (2016) focuses on a domestic service-learning program, these same challenges may be experienced in ISL programs. Further research is needed to investigate whether this is the case.

The limited research, consisting of only two studies that directly investigated local partners' perspectives regarding ISL, indicates that more research is needed for a better understanding of the experiences of local partners. Further research involving the perspective of international partners, from more than one international location, and in the context of an interprofessional ISL experience, have yet to be evaluated.

Responding to this need for consideration of local partners' views, this pilot study aims to provide preliminary information which can inform future, larger-scale research with local partners. This research asks: what are local partners' perspectives on an interprofessional ISL experience undertaken in two international locations, Vietnam and Timor-Leste, between 2014 and 2016 ?

\section{Methods}

A university Medical Research Ethics Committee gave approval for this qualitative research. The university has partnered with community disability and rehabilitation services in Vietnam since 2011 and in Timor-Leste since 2014 (Crawford et al., 2017). These partnerships have provided physiotherapy, speech pathology and occupational therapy students with the opportunity to complete a student placement in an ISL context as part of their study programs. This pilot study aims to understand the perspectives of local partners in both countries.

Interpretive description (Thorne, 2016; Thorne et al., 1997) informed this research. Expert accounts from local in-country partners were thematically analysed (Braun \& Clarke, 2006) by the researchers, who have practice experience, which could further inform analysis and interpretation (Thorne, 2016). All researchers had also been administrators, coordinators, educators or students in the programs studied. Thus the themes identified are inherently linked to the researchers' perspectives, as is the case in any qualitative research (Patton, 2002). Consequently, the findings hold greater legitimacy due to strong links to practice (Thorne, 2016; Thorne et al., 2004). Based on researchers' practice working in Vietnam and Timor-Leste, questions were presented in a manner that was culturally appropriate based on researchers'. 
Interpretation of the findings was also rooted in practice experience. For instance, in the findings regarding preparation for local staff training, one participant's comment clearly reflected what happens in practice when the ISL student placements occur. Given the researchers' roles in both practice and research, ongoing reflexivity (Patton, 2002) through team meetings, in which the analysis was discussed, and review of the audit trail by separate members of the team throughout analysis were vital to ensuring the reliability of the research.

\section{Research context}

The organisation in Timor-Leste was a government-managed service until 2016 when it became an independent non-government organisation. It delivers adult and paediatric rehabilitation and disability services through in-patient, out-patient, home-visit (since 2017, in partnership with the ISL program) and community-based rehabilitation outreach programs. It has partnered with this ISL project since 2014 and in 2016, it began to increase its ISL partnerships in order to work with other universities. ISL students in this project work alongside local staff to deliver physiotherapy, occupational therapy, speech pathology, community-based rehabilitation, and wheelchair prescription and modification. Supervised clinical services, resource development and training workshops are delivered by ISL students.

The organisation in Vietnam is a non-government association and a charity to support children with disabilities and their families from urban and rural locations. The organisation has many longstanding ISL partnerships with a range of universities. The ISL project in this study has been working in partnership with the Vietnamese organisation since 2011. ISL in this project involves supervised students providing sustainable interventions and consultation in schools, early intervention centres and vocational training locations along with staff training.

\section{Participants}

Four local partners agreed to participate and completed the post-placement questionnaire over three years (2014-16). Three participants from Vietnam responded to surveys in 2014 (LP0101 and LP0102) and 2016 (LP0103), and one participant from Timor-Leste responded to the survey in 2015 (LP02). To maintain anonymity of the local partner participants, details of their organisations, organisation types, roles, ages, genders and other details were either not collected or cannot be provided. Local partners who were invited to respond to the questionnaire included service managers, allied health staff, and support staff who worked in disability and rehabilitation services in Vietnam and Timor-Leste. In-country liaison workers for the service-learning program who supported connections between the university and the clinic services were also invited to participate; however, no one in this role participated.

\section{Questionnaire}

Qualitative and quantitative questions were included in the purpose-designed post-placement questionnaire. Only qualitative data was analysed in this study. Key local partner stakeholders spoke English and most communication between the university staff and local partners was conducted in English or via translation arrangements with other staff members. The survey was emailed to local partners by educators after completion of the ISL each year. Qualitative questions, in English, asked local partners about their perspectives on a) the outcomes for their organisations, their clients, and staff, along with b) suggestions for improvements regarding the work completed by students and educators, communications, and support and information provided before the placements commenced. The questionnaire also provided space for local partners to include their own additional comments. Between 2014 and 2016, questionnaires were sent to local partners after the ISL placements concluded. The final response was received in 2017.

\section{Data analysis}

Thematic analysis was carried out to examine the data inductively (Braun \& Clarke, 2006). One researcher coded each section of the data, which had been typed into a spreadsheet. Eighty percent agreement was achieved when the coding was examined by an independent researcher. Nine out of 45 
coded sections were reviewed after the independent researcher checked coding for representation of the data, semantics of the original codes were discussed, and one code was revised to reflect more closely the content of the data. Review and revision of codes resulted in $100 \%$ agreement between the researcher who carried out the original coding and the second, independent, code reviewer.

Codes were then grouped into themes by the first researcher and a third independent researcher reviewed themes with examples of participant responses within each theme to confirm their identification. The third researcher agreed with the coding and theme development. All researchers then reviewed the descriptions of the themes and associated quotes. All researchers agreed with the themes. In some instances descriptions of themes were not clear to other research team members and the descriptions of the themes were revised for clarity. Researcher reflexivity through reflective discussions, reviewing of coding and theming by independent team members, as well as maintaining an audit trail of analysis, ensured trustworthiness (Patton, 2002).

\section{Findings}

Three themes relating to local partners' perspectives were identified:

(1) benefits of the partnerships;

(2) importance of communication; and

(3) respectful engagement for collaboration.

\section{Benefits of the partnerships}

The main benefit of the ISL programs was the increase in local partners' skills and knowledge (19 responses, 4 participants). Other benefits to the local partners included gaining enhanced assessment and intervention strategies ( 9 responses, 3 participants); strengthening service quality (6 responses, 3 participants); providing resources ( 1 response, 1 participant); strengthening the organisation's reputation (1 response, 1 participant); and addressing oppressive practices ( 1 response, 1 participant).

Skills and knowledge were increased through modelling, suggestion and discussion, and formal training sessions. LP0101 explicitly stated that one of the best outcomes for their organisation was 'enhancing skill for our organisation's early intervention and special education supervision team (and) effective cooperation of interdisciplinary student groups in helping for children with disabilities is a very good model for our organisation to learn'. LP0103 noted that one of the best outcomes was 'gaining new knowledge through the training/workshop and individual case analysis at their classes'.

Enhancement of client assessment and intervention strategies included a focus on independence and opportunities for engagement in activities for service users, holistic observation, interdisciplinary planning, and more individualised treatment plans. LP0103 explained, 'the network of professional exchange between our organisation's team and students from (the University) is set up so that the supporting strategies for children with disabilities can be share(d) and discuss(ed)'. Similarly, LP0102 explained what they observed of the holistic approach to assessment and intervention planning: 'children were holistically observed by interdisciplinary team - physical therapy (physiotherapy) student, speech pathology student, occupational therapy student - so the individual plans were developed more closer with the children's ability'. LP0102 explained, 'with the enthusiastic support of the students and clinical educator, the families with disabled children are more aware of supporting their child as well as aware of making use of domestic objects as materials and toys'.

Considering quality improvements, LP0103 stated that 'the suggestions and comment of UQ students and clinical educators are helpful cues for our organisation to improve the quality of early intervention and special education services', exemplifying the strengthening of service quality through the partnership. LP0101 briefly observed that the impact of the partnership contributes to 'preventing violence and exclusion at school'. 
According to local partner participants' responses, these benefits arose out of professional exchanges which included training workshops, modelling of professional and clinical behaviours and techniques, open discussion, cultural exchange, information sharing, and exposure to different ways of delivering services.

\section{Importance of communication}

From local partners' responses, the analysis identified underpinning elements that contributed to the mutually beneficial partnerships including communication (10 responses, 3 participants) which supported a relational approach (10 responses, 3 participants) to working with services.

Local partners viewed effective communication as regular and structured communication, including ongoing meetings such as 'weekly meeting(s)' (LP0101) and formal training sessions. For example, LP0102 explained that they valued the students 'focusing on training for the staff'. They also valued flexible communication; for example, LP0101 explained that it was useful that an 'urgent meeting or call can be done for urgent cases'.

A beneficial relational approach to working with local services was underpinned by effective and ongoing communication, according to local partners. This included building partnerships and cooperating. LP02 described this as when 'cultural exchange and social network(s) were established'.

\section{Respectful engagement for collaboration}

Improvements sought from university partners included a need to draw more strongly on the strengths of the local partners ( 8 responses, 3 participants); more time dedicated to preparation for the student placement context ( 6 responses, 4 participants); and more regular communication ( 2 responses, 2 participants). While the first two themes indicate that university partners engaged with local partners in a respectful manner, these findings have been interpreted as a call for a heightened sensitivity to the need for respectful engagement with local partners for effective collaboration.

Local partners' knowledge and existing organisation structures in the local context were noted as important strengths to draw on for respectful engagement. A desire was expressed for university partners to include local partners' knowledge and perspectives in planning and reviewing placements. One local partner participant shared that local staff within the organisation could have provided more feedback, although the feedback process - occurring via email after the placements were complete - appears to have been a barrier to local partner contributions. LP02 explained, 'supervisors should prepare review form during the placement and need to be filled (in) by staffs and managers of our organisation one or two days before the end of placement. This is suggested due to the experiences for the last two placements as almost none of them provided feedback about students' placement'.

Regarding the need for improvements in preparation processes for respectful engagement, LP0101 indicated that more information could be provided at an earlier time prior to the placements occurring: 'the information of the placement should be provided at least 3 months before for administrative preparation'. This participant also suggested that 'the interpreter should be introduced to our organisation before the placement (if possible) so that we can have good preparation' and that 'the goal or required work of the placement can be provided for our organisation before'. LP02 also suggested that preparation for the placements could be improved, for example, 'intended training subjects need to be informed and communicated (discussed) with our organisation before arrival to see whether the subject has been learned or taught by other institutions or not? So, students may also do some preparation before arrival'. These training topics are usually discussed and decided while students and educators are incountry, and participant LP02 has indicated that the discussions may be more beneficial prior to the students arriving.

While regular and structured communication such as meetings and presentations was seen as an underpinning element that contributed to the effectiveness of partnerships, it was also raised when describing what could be done better by students and educators. For instance, LP02 said 'more presentations should be organised to share knowledge and skills for our organisation in supporting 
children with special needs', and LP0102 explained that 'by the end of every visit (clinic session) there should be short meetings to discuss on any change or suggestion through which our organisation staff can learn more'. Debriefing processes such as that suggested by LP0102 would demonstrate further respectful engagement whereby ISL students and staff can share skills, knowledge and reasoning through discursive processes with local partners.

\section{Discussion}

The aim of this research was to understand local partners' perspectives on interprofessional ISL partnerships between a university (to provide student placement experiences for health professional students) and two international locations (Vietnam and Timor-Leste). This pilot project has identified preliminary findings about the benefits of the partnerships, the importance of communication for their effectiveness, and enhancing respectful engagement for collaboration as an area for further improvement. ISL in low- and middle-income countries as part of tertiary health professional education is an increasing trend (Crump et al., 2010; Saffran, 2013), and may benefit participating students, faculty members, individual recipients of services, the host community, and local partner organisations and their staff (Rinaldo et al., 2015).

This research has outlined the benefits identified by a small sample of local community partners in Vietnam and Timor-Leste. Participating local partners saw benefits of the partnerships, including strengthened local skills and knowledge, enhanced assessment and intervention strategies and service quality, provision of resources, reinforcement of the organisation's reputation, and confrontation of oppressive practices. The findings from this research are consistent with that of previous studies (Hayward \& Li, 2017; Hayward et al., 2015) which considered the perspectives of local partners in ISL from low- and middle-income countries. This indicates that knowledge exchange, skill development for local health professionals, and access to resources are priorities for health professionals in low- and middle-income countries and are valued as ISL partnership outcomes. All studies have been small scale, and this emerging evidence requires further investigation.

Effective formal communication and a relational approach were seen as factors that contribute to beneficial partnerships in these preliminary findings. This research indicates that local partners gain new knowledge and skills through observing students' model practice, through formal training and meetings, and through ongoing discussion of cases. Implications for practice are that it may best benefit local partners if the effects of modelling effective practice, the importance of communication, relationship building, delivering training, and engaging in collaborative case discussions, are emphasised to students prior to placements, while also ensuring that these strategies are supported by educators throughout placements. Pre-placement preparation, ongoing educator feedback and assessment documents might reflect these key messages. In light of these findings, consideration should also be given to the importance of establishing sustainable methods of knowledge sharing and maintenance of new skills for local staff after placements have been completed.

Service-learning programs in low- and middle-income countries can provide additional clinical assistance in under-resourced settings and, at the same time, provide students with learning opportunities in intercultural contexts that highlight health and health-care disparities (Decamp, 2007; Reisch, 2011). Such programs should be carried out with care and with sensitivity to the complex ethical contexts in which they occur. In this pilot research, the improvements sought by local partners included a desire for more communication in the form of meetings and training sessions, suggestions that students and educators could draw more on local partners' strengths, and a need for additional preparation with local partners prior to the placements commencing. These findings highlight different challenges to those identified by local partners in previous research by Hayward and colleagues (Hayward \& Li, 2017; Hayward et al., 2015): cultural barriers, lack of local language fluency, and concerns over the sustainability of newly acquired skills. The dissimilarities in findings may be due to the different regional contexts. Hayward et al. (2015) conducted their study in a South American context whereas the current research has been conducted in the Asia-Pacific region. The differences in perceptions regarding improvements and challenges may be due to the different data collection methods, different professional backgrounds of students and educators involved, or different deliveries of the ISL programs. Furthermore, 
local service users, who have not been included in this research, might have yet another perspective. More research is needed to better understand a broad range of local partners' and service users' perspectives on what could be done better in ISL in low- and middle-income countries. Nonetheless, challenges and areas for improvement have been identified by local partners, indicating that all faculty staff involved in organising these programs should continuously seek feedback from local partners and work collaboratively towards mutually beneficial outcomes, using processes that are suitable for all stakeholders.

While limited, these research findings lend support to the adoption of principles and guidelines that encourage sustainable and mutually beneficial outcomes in ISL in low- and middle-income countries such as those suggested by McKinnon \& Fealy (2011) and Crump et al. (2010). As regards these research findings, particular emphasis should be placed on guidelines about relationship building and preparation in partnership with local partners prior to arriving in the host country, not just on preparing students for in-country experiences. This may be particularly important for educators travelling with students to lowand middle-income countries for the first time, as they might not have existing relationships or shared experience with local partners to draw on.

\section{Limitations}

Limitations of this research pertain to the context specific nature of the research, sample size, and data collection methods. The research is specific to the experiences of local partners in two countries in the Asia-Pacific region, who have worked with a single university ISL program. Transferability of the findings to other ISL programs and other regional contexts is tenuous and context specific information should be prioritised when considering these findings in relation to other ISL programs or in other countries or regions.

A small sample size of four respondents may mean that the findings are not representative of all local partner stakeholders, such as all staff within the partner organisations. Other similar research has also included small numbers of participants, for example, six local partners (Hayward et al., 2015). Despite the limited sample, patterns were identifiable within the pilot study data due to consistencies between the respondents' perspectives. Further larger-scale research is required to understand if these perspectives are shared by other ISL local partner stakeholders and service users who can provide further invaluable, contextualised insights into service quality, appropriateness and effectiveness. Given that little research including local partner and local service user perspectives on ISL in low- and middle-income countries has been carried out (Hayward \& Li, 2017), and the importance of considering local partners' perspectives in research and evaluation of these partnerships, this research provides some preliminary findings on which future research that considers these integral perspectives may build.

Surveys, in English, with written responses were provided to local partners after the university partners had departed. Surveys were sent by educators involved in the program. Therefore, respondents' feedback may have been influenced by established relationships and desire for positive outcomes to ensure return of students each year. Only those with English language proficiency or access to a translator could complete the surveys. The research findings also indicate that local partners would have liked to provide more input in the research and evaluation, and that this may have been effective if conducted prior to the educators' and students' departure. Interviews or focus groups may provide additional opportunities for a broader range of local partners to share their perspectives. Interview or focus group methodology may obtain richer data and allow for follow up questions to be asked in order to clarify understandings of local partners' perspectives. Having an independent researcher who is not an educator or ISL student conduct interviews, in partnership with an interpreter, would resolve issues pertaining to language barriers and existing relationships with the educators.

\section{Conclusion}

This research aimed to understand local partners' perspectives on ISL programs in Vietnam and TimorLeste that involved speech pathology, physiotherapy, and occupational therapy student placements. A small sample of local partners responded to surveys and analysis that revealed benefits of ISL for local 
partners including skill and knowledge exchange, enhanced assessment and intervention strategies, and increasing service quality. Analysis revealed the importance of communication and suggestions for enhancing respectful engagement in collaboration. While further research using data collection methods that aim to develop deeper understandings of a wider range of local partners is needed, this research contributes to an emerging evidence base for ISL regarding the important views of local partners from low- and middle-income countries.

\section{Acknowledgements}

The authors would like to acknowledge our local partners' participation in this research and their commitment to ongoing partnerships.

\section{Sources of funding}

University of Queensland New Staff Grant from 2016-2018.

\section{Ethical approval}

The University of Queensland. Approval number 2009001668

\section{ORCID}

Emma Crawford:

https://orcid.org/0000-0001-8958-0563

Anne E. Hill:

https://orcid.org/0000-0002-6272-9433

Anne-Maree Caine:

https://orcid.org/0000-0002-0434-0075

Lucy Hunter:

https://orcid.org/0000-0001-5004-0746

Allison Mandrusiak:

https://orcid.org/0000-0003-4180-9167

Ruth Dunwoodie:

https://orcid.org/0000-0003-2166-5848

Amy Fagan:

https://orcid.org/0000-0002-3093-5785

Teresa Quinlan

https://orcid.org/0000-0003-0909-5141

Nataya Branjerdporn:

https://orcid.org/0000-0002-0263-9946

Lisa Anemaat:

https://orcid.org/0000-0001-7410-4652

\section{References}

Atuyambe, L. M., Baingana, R. K., Kibira, S. P. S., Katahoire, A., Okello, E., Mafigiri, D. K., Ayebare, F., Oboke, H., Acio, C., Muggaga, K., Mbalinda, S., Nabaggala, R., Ruzaaza, G., Arubaku, W., Mary, S., Akera, P., Tumwine, J. K., Peters, D. H., \& Sewankambo, N. K. (2016).

Undergraduate students' contributions to health service delivery through community-based education: A qualitative study by the MESAU Consortium in Uganda. BMC Medical Education, 16 (123). doi: 10.1186/s12909-016-0626-0

Beaman, A., Asano, R., Sibbritt, D., Newton, P.J., \& Davidson, P.M. (2018). Global service learning and health systems strengthening: An integrative literature review. Heliyon, 4 (8), e00713. doi: 10.1016/j.heliyon.2018.e00713 
Beran, D., Aebischer Perone, S., Alcoba, G., Bischoff, A., Bussien, C.-L., Eperon, G., Hagon, O., Bausch, F. J., Perone, N., Vogel, T, \& Chappuis, F. (2016). Partnerships in global health and collaborative governance: Lessons learnt from the Division of Tropical and Humanitarian Medicine at the Geneva University Hospitals. Globalalization and Health, 12 (1), 14. doi: 10.1186/s12992-016-0156-X

Bowen, S., \& Martens, P. J. (2006). A model for collaborative evaluation of university-community partnerships. Journal of Epidemiology and Community Health, 60 (10), 902-907. doi: 10.1136/jech.2005.040881

Braun, V., \& Clarke, V. (2006). Using thematic analysis in psychology. Qualitative Research in Psychology, 3 (2), 77-101. doi: 10.1191/1478088706qp063oa

Chapman, D. D. (2018). The ethics of international service learning as a pedagogical development practice: A Canadian study. Third World Quarterly, 39 (10), 1899-1922. doi: 10.1080/01436597.2016.1175935

Cipriani, J. (2017). Integration of International Service Learning in developing countries within occupational therapy education: Process and implications. Occupational Therapy in Health Care, 31 (1), 61-71. doi: 10.1080/07380577.2016.1244734

Crawford, E., Caine, A.-M., Hunter, L., Hill, A. E., Mandrusiak, A., Anemaat, L., Dunwoodie, R., Fagan, A., \& Quinlan, T. (2017). Service learning in developing countries: Student outcomes including personal successes, seeing the world in new ways, and developing as health professionals. Journal of Interprofessional Education \& Practice, 9 (1), 74-81. doi: 10.1016/j.xjep.2017.08.006

Crump, J. A., Sugarman, J., \& the Working Group on Ethics Guidelines for Global Health Training (WEIGHT). (2010). Ethics and best practice guidelines for training experiences in global health. American Journal of Tropical Medicine and Hygiene, 83 (6), 1178-1182. doi: 10.4269/ajtmh.2010.10-0527

Curtin, A. J., Martins, D. C., \& Schwartz-Barcott, D. (2015). A mixed methods evaluation of an international service learning program in the Dominican Republic. Public Health Nursing, 32 (1), 58-67. doi: 10.1111/phn.12117

Decamp, M. (2007). Scrutinizing global short-term medical outreach. Hastings Center Report, 37 (6), 2123. doi: $10.1353 /$ hcr.2007.0096

El-Jardali, F., Ataya, N., \& Fadlallah, R. (2018). Changing roles of universities in the era of SDGs: Rising up to the global challenge through institutionalising partnerships with governments and communities. Health Research Policy and Systems, 16 (1), 38. doi: 10.1186/s12961-018-0318-9

Hayward, L., \& Li, L. (2017). Sustaining and improving an international service-learning partnership: Evaluation of an evidence-based service delivery model. Physiotherapy Theory and Practice, 33 (6), 475-489. doi: 10.1080/09593985.2017.1318425

Hayward, L., Li, L., Venere, K., \& Pallais, A. (2015). Enhancements to an International Service-Learning model: Integration of program alumni and global stakeholder feedback. Journal of Physical Therapy Education, 29 (2), 43-53. doi: 10.1097/00001416-201529020-00007

Jesus, J. E., 2010. Ethical challenges and considerations of short-term international medical initiatives: An excursion to Ghana as a case study. Annals of Emergency Medicine, 55 (1), 17-22. doi: 10.1016/j.annemergmed.2009.07.014

Johnson, A. M., \& Howell, D. M. (2017). International service learning and interprofessional education in Ecuador: Findings from a phenomenology study with students from four professions. Journal of Interprofessional Care, 31 (2), 245-254. doi: 10.1080/13561820.2016.1262337

Landry, M., Nixon, S., Raman, S., Taylor, J., \& Tepper, J. (2012). Global Health Experiences (GHEs) in physical therapist education: Balancing moral imperative with inherent moral hazard. Journal of Physical Therapy Education, 26 (1), 24-28. doi: 10.1097/00001416-201210000-00006

Lattanzi, J. B., \& Pechak, C. (2011). A conceptual framework for international service-learning course planning: Promoting a foundation for ethical practice in the physical therapy and occupational therapy professions. Journal of Allied Health, 40 (2), 103-109.

Loh, L. C., Cherniak, W., Dreifuss, B. A., Dacso, M. M., Lin, H. C., \& Evert, J. (2015). Short term global health experiences and local partnership models: A framework. Globalization and Health, 11, 50. doi:10.1186/s12992-015-0135-7 
McKinnon, T. H., \& Fealy, G. M. (2011). Core principles for developing global service-learning programs in nursing. Nursing Education Perspective, 32 (2), 95-101. doi: 10.5480/1536-502632.2.95

Memmott, R. J., Coverston, C. R., Heise, B. A., Williams, M., Maughan, E. D., Kohl, J., \& Palmer, S. (2010). Practical considerations in establishing sustainable international nursing experiences. Nursing Education Perspective, 31 (5), 298-302. doi: 10.1043/1536-5026-31.5.298

Musolino, G. M., \& Feehan, P. G., (2004). Enhancing diversity through mentorship: The nurturing potential of service learning. Journal of Physical Therapy Education, 80 (5), S53. doi: 10.1097/00001416-200401000-00005

Patton, M. Q. (2002). Qualitative research and evaluation methods. Sage Publications.

Pechak, C. M., \& Black, J. D. (2013). Benefits and challenges of international clinical education from a US-based physiotherapist faculty perspective. Physiotherapy Research International, 18 (4), 239-249. doi: 10.1002/pri.1556

Pechak, C. M., \& Thompson, M. (2009). A conceptual model of optimal international service-learning and its application to global health initiatives in rehabilitation. Physical Therapy, 89 (11), 1192 1204. doi: $10.2522 /$ ptj.20080378

Plumb, E., Roe, K., Plumb, J., Sepe, P., Soin, K., Ramirez, A., Baganizi, E., Simmons, R., \& Khubchandani, J. (2013). The use of international service learning initiatives for global health education: Case studies from Rwanda and Mexico. Health Promotion Practice, 14 (3), 334-342. doi: $10.1177 / 1524839913476516$

Reisch, R. (2011). International service learning programs: Ethical issues and recommendations. Developing World Bioethics, 11 (2), 93-98. doi:10.1111/j.1471-8847.2011.00299.x

Rinaldo, S. B., Davis, D. F., \& Borunda, J. (2015). Delivering value to community partners in servicelearning projects. Journal of Community Engagement and Scholarship, 8 (1), 115-124.

Sabo, S., de Zapien, J., Teufel-Shone, N., Rosales, C., Bergsma, L., \& Taren, D. (2015). Service learning: A vehicle for building health equity and eliminating health disparities. American Journal of Public Health, 105 Supplement 1, S38-43. doi: 10.2105/ajph.2014.302364

Saffran, L. (2013). Dancing through Cape Coast: Ethical and practical considerations for health-related service-learning programs. Academic Medicine, 88 (9), 1212-1214. doi: 10.1097/ACM.0b013e31829ec9f2

Thorne, S. (2016). Interpretive description: Qualitative research for applied practice, 2 nd edn. Routledge.

Thorne, S., Kirkham, S. R., \& MacDonald-Emes, J. (1997). Interpretive description: A noncategorical qualitative alternative for developing nursing knowledge. Research in Nursing and Health, 20 (2), 169-177. doi.org/10.1002/(SICI)1098-240X(199704)20:2<169::AID-NUR9>3.0.CO;2-I

Thorne, S., Reimer Kirkham, S., \& O'Flynn-Magee, K. (2004). The analytic challenge in interpretive description. International Journal of Qualitative Methods, 3 (1), 1-11. doi: $10.1177 / 160940690400300101$

World Bank. (2019). World Bank country and lending groups. Retrieved from https://datahelpdesk.worldbank.org/knowledgebase/articles/906519-world-bank-country-andlending-groups 